\title{
The Utilization of Long-Acting Reversible Contraception and Associated Factors Among Women in Indonesia
}

\author{
Maria Gayatri ${ }^{1}$ \\ ${ }^{1}$ Center for Research and Development of Family Planning and Family Welfare, National Population and Family \\ Planning Board (BKKBN), Jakarta, Indonesia \\ Correspondance: Maria Gayatri, Center for Research and Development of Family Planning and Family Welfare, \\ National Population and Family Planning Board, Jalan Permata no. 1, Halim Perdana Kusuma, Jakarta, Indonesia. \\ Email: maria_gaya3@yahoo.co.id
}

Received: January 26, 2020 Accepted: February 20, 2020 Online Published: February 24, 2020

doi:10.5539/gjhs.v12n3p110 URL: https://doi.org/10.5539/gjhs.v12n3p110

\begin{abstract}
Long-acting reversible contraceptives (LARCs), consist of IUD and implats, were effective and efficient methods in preventing the pregnancy. However, the used of these methods in Indonesia was still low. This study sought to explore LARC utilization trends and the factors influencing LARC used among reproductive women in Indonesia. This research analyzed data from the Indonesia Demographic and Health Survey 2017. Respondents in this study were women who currently used modern contraceptive methods. A total of 20,409 women who used modern methods were included in the analysis. Descriptive analysis was performed using chi-square and percentages. Logistic regression with complex sample design was used to determine the associated factors in LARC utilization. Among women in reproductive age who currently used modern contraception, IUDs and implants were viewed particularly unfavorably which only $16.5 \%$ of women used LARC. Findings highlighted that higher LARC use among reproductive age women in Indonesia correlated with higher parity, older women, higher education, working women, desire to limit the pregnancy in the future and more visited by fieldworkers in the last 12 months. This study underscored that even though only $4 \%$ of respondents were visited by fieldworkers, the utilize of LARC was higher among women who visited by fieldworkers. This study suggests that communication skills among fieldworker need to be enhanced to do counselling and work closely with the community member.
\end{abstract}

Keywords: intrauterine devices, implants, long-acting, reversible contraceptives

\section{Introduction}

Family planning is cost-effective intervention to improve maternal and child health through reducing high risk pregnancies and lowering unintended pregnancies (Smith, Ashford, Gribble, \& Clifton, 2009; Starbird, Norton, \& Marcus, 2016). The Indonesia family planning program since its initiation in early 1970 s to early 2000 s has been successful in reducing fertility and maternal mortality. 63.6\% married women used contraceptive methods in Indonesia (National Population and Family Planning Board, Statistics Indonesia, Ministry of Health, \& ICF, 2018). Despite the high prevalence of contraceptive use in Indonesia, it was reported that $8.1 \%$ of current pregnancies were mistimed and $7.1 \%$ of pregnancies were unwanted. Unwanted pregnancies in Indonesia were related to higher births and older women.

Government of Indonesia recommended Long-acting and permanent methods (LAPM) as it is mentioned as one of targeted outcome in the Indonesia Midterm National Development Plan 2020-2024. Long-acting reversible contraception reduce client's compliance and method's failure because of inconsistent and incorrect method use (Frost \& Darroch, 2008; Stoddard, McNicholas, \& Peipert, 2011). Long-acting methods were cost-effective methods in reducing the risk of unintended pregnancies, long-lasting, convenient, it did not require frequent visits to the health providers and highly effective methods with less than 1\% failure rate in a year (Stoddard et al., 2011; Trussell, 2004; Whitaker et al., 2008). At 1 year, LARC have higher rates of continuation rates (more than 90\%) and user satisfaction, and first-line contraceptive method to avoid unintended pregnancy in longer time (Peipert et al., 2013). However, despite the strong efficacy and acceptability of LARCs, the used of LARCs was still low in Indonesia. In 2017, IUDs and implants were used by only less than $10 \%$ of women in reproductive age.

Prior researches have documented a variety of factors that may influence the adoption of LARCs. Demographic characteristics such as women's age (Adedini, Omisakin, \& Somefun, 2019; Asad, Hebert, Andridge, Nguyen, \& 
Gallo, 2019; Austad, Shah, \& Rohloff, 2018; Bhandari, Pokhrel, Gabrielle, \& Amatya, 2019; Dempsey, Billingsley, Savage, \& Korte, 2012; Finer, Jerman, \& Kavanaugh, 2012; Harzif, Mariana, Malik, Silvia, \& Lovita, 2019; Weber, Briggs, \& Hanson, 2017), parity (Asad et al., 2019; Bhandari et al., 2019; Finer et al., 2012; Mazzei et al., 2019), family welfare (Adedini et al., 2019; Bhandari et al., 2019; Fekadu, Omigbodun, Roberts, \& Yalew, 2019), women's knowledge (Dempsey et al., 2012; Harzif et al., 2019; Mazzei et al., 2019), women's education (Adedini et al., 2019; Asad et al., 2019; Mazzei et al., 2019; Ontiri et al., 2019; Secura \& McNicholas, 2013), husband education (Bhandari et al., 2019), women's occupation (Adedini et al., 2019; Fekadu et al., 2019), husband's occupation (Bhandari et al., 2019), religion (Mazzei et al., 2019; Ontiri et al., 2019), desire for children in the future (Bhandari et al., 2019; Ontiri et al., 2019), accessibility (Secura \& McNicholas, 2013) were documented as significant predictors of LARC used. Health related factors for LARC adoption were health workers skills (Harzif et al., 2019; Ontiri et al., 2019), counselling (Mazzei et al., 2019; Secura \& McNicholas, 2013) and history of abortion (Fekadu et al., 2019). Other factors such as cost of contraception (Adedini et al., 2019; Finer et al., 2012; Harzif et al., 2019; Secura \& McNicholas, 2013), health worker training on LARC (Mazzei et al., 2019; Secura \& McNicholas, 2013), logistical support (Mazzei et al., 2019; Secura \& McNicholas, 2013), partner's support (Mazzei et al., 2019), myths (Secura \& McNicholas, 2013) and exposure to mass media (Adedini et al., 2019) were also related to the used of LARC.

\subsection{Aim of The Study}

The study aimed to estimate the predictors of the utilization of long-acting reversible contraceptives among married women aged 15-49 years in Indonesia.

\section{Meterials and Methods}

\subsection{Data}

Data in this analysis came from the Demographic and Health Survey, a national representative household survey that conducted about every 5 years and implemented in 90 countries to provide data related to population, health and nutrition. Indonesia Demographic and Health Survey (IDHS) 2017 was implemented with technical assistance from the ICF through the Demographic and Health Surveys (DHS) Program. Indonesia Demographic and Health Survey provided national and sub-national (provincial level) information on fertility, maternal health, child health, HIV/AIDS and women empowerment (National Population and Family Planning Board et al., 2018). This study analyzed the women questionnaire which collected information on all women age 15-49 years.

This study included data that met the following inclusion criteria: (1) data collected from women's questionnaire in the 2017 IDHS as the most recent IDHS, (2) women age 15-49 years who married or lived with partner, (3) women currently used modern contraception at the time of interview, (4) final dataset were available for download and analysis as of January 2020. The final study dataset included 34 Provinces in Indonesia. Total sample size was 20,409 women which ranged from 33 women in North Kalimantan (the newest Province in Indonesia) to 4,307 in West Java Province.

\subsection{Study Variables}

The main outcome variable in this analysis was the used of modern contraceptive methods. In the survey, women were asked about their current method to avoid getting pregnant. Pregnant women at the time of survey would be coded 0 as not currently using. Only those women who used modern contraception will included in this analysis. Those women will be grouped into women who used IUDs and implants (LARC) and women who used other modern contraceptive methods (female sterilization, male sterilization, oral contraceptives, injectables, condom, and LAM). We excluded women who used traditional contraception (rhythm, withdrawal or other traditional methods) and not used any contraception.

In addition, for explanatory variables, women answered questions about their socioeconomic and their contraceptive related factors. We assessed eleven variables as possible predictors: women's age (15-19, 20-34, $35-49$ years), parity (0,1-2, 3 or more), education (no education and primary, secondary and higher), occupation of women (not working, agriculture and others), future desire of children (no more and have another in the future), visited by family planning fieldworker in the 12 months (no, yes), knowledge about fertile day (no, yes), mass media exposure (no exposure, at least one exposure), wealth index (less wealthy, middle, wealthiest), place pf residence (urban, rural) and region (Java-Bali, outside Java-Bali). Those possible predictors were used due to their association with long acting contraceptive used in the previous studies (Adedini et al., 2019; Bhandari et al., 2019; Fekadu et al., 2019). 


\subsection{Statistical Analysis}

The denominator used in this study was women aged 15-49 years (married or cohabitation) who used modern contraceptive methods at the time of the survey in 2017. Logistic regression model is appropriate in assessing correlation of long-acting reversible contraception. The logistic model was built by assessing each possible predictor individually with the outcome interest, the used of long-acting reversible contraceptives (yes/no). All significant predictors in the bivariate analysis with LARC used, $\mathrm{p}$-value $<0.05$, were included in the initial multivariable logistic model. The final logistic model included only significant predictors after adjusted by all confounders. The constant effect of a predictor on the likelihood of the outcome were expressed as odds ratio at $95 \%$ confidence intervals. All the analysis used sample weighting adjustments by divide its sample weight 1000000 then it was normalized so the sample size after weighted was similar to unweighted sample size (ICF, 2018). Complex sample analysis is also used in the survey design which design such as stratifying the population, sampling cluster or unequal probabilities in respondent's selection (some respondents had higher probability than others to be chosen as sample's study) (Sakshaug \& West, 2014). The data analysis was done using do-file Stata 15.1.

\subsection{Ethical Considerations}

This research used data collected at the 2017 Indonesia Demographic and Health Survey, downloaded by registering with the DHS website. The names and addresses of the respondents are not included while downloading the data. Therefore, no separate ethics approval is required for using the data for this paper.

\section{Results}

\subsection{Levels and Trends in Contraceptive Used in Indonesia}

Modern contraceptive used among married women 15-49 years in Indonesia increased gradually during three decades until 2017 (Figure 1). However, the used of IUDs and implants dropped continuously from $16.4 \%$ in 1991 to $7.2 \%$ in 2012 then it started to increase in 2017 to $9.4 \%$.

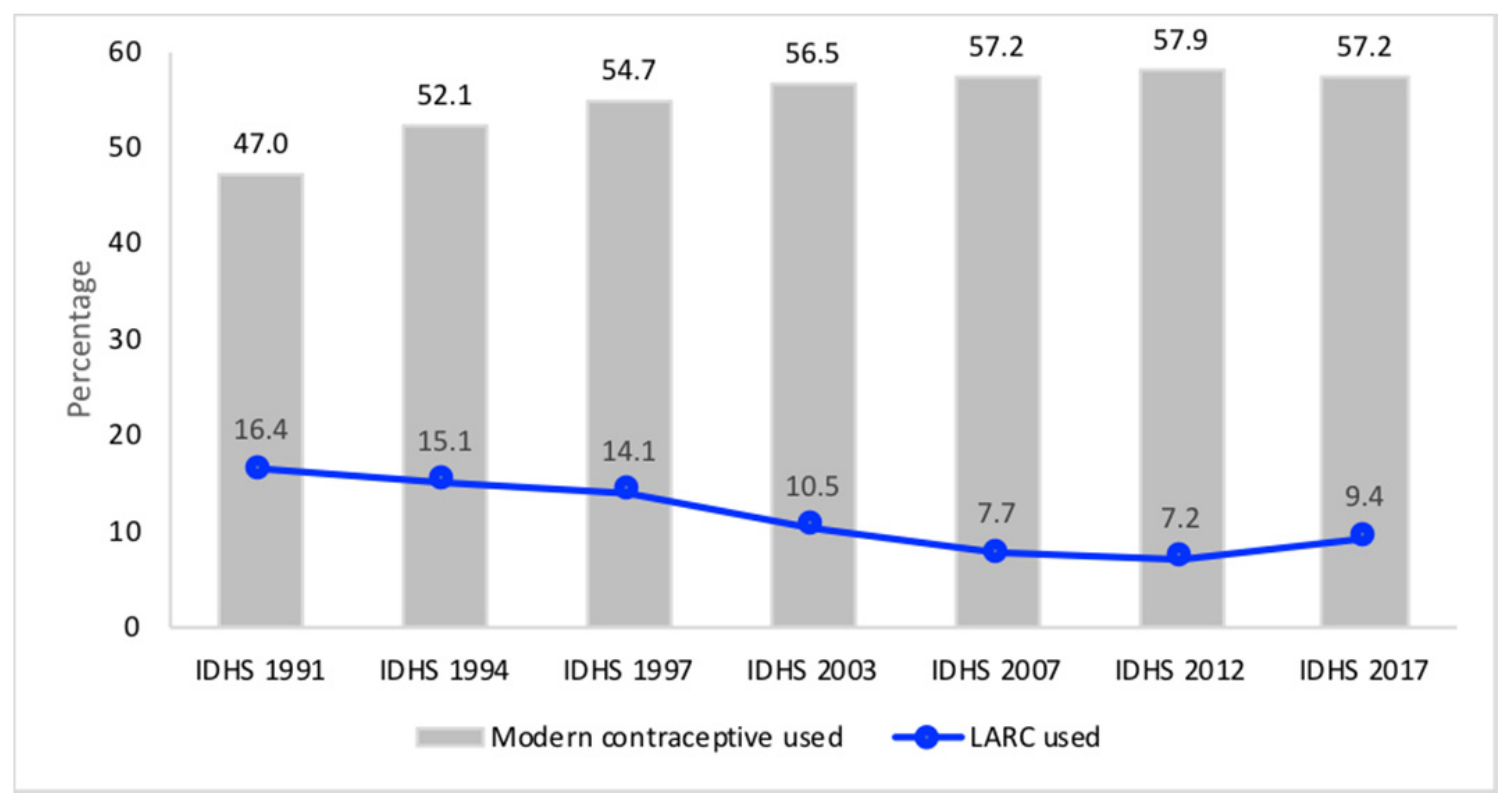

Figure 1. The used of modern contraceptive methods and LARC in Indonesia, 1991-2017

\subsection{Predictors of the Used of LARC}

Of the 49,627 women age 15-49 years as respondents in IDHS 2017, there were 20,409 women who met the criterion for this analysis as currently married women who used modern contraceptive methods (after excluding women who did not use any contraception and whose who used traditional methods). Of the modern contraceptive users, it was estimated that $9.4 \%$ of women used LARC methods. Table 1 provides the demographic and reproductive characteristics stratified by LARC and non LARC methods. In the descriptive analysis, $54.69 \%$ of the respondents were aged 35-49 years, whereas $43.81 \%$ were aged $20-34$ years and only $1.5 \%$ were aged $15-19$ years. The majority of the respondents had secondary education (52.55\%) whereas only about $10 \%$ had higher education. 
About $62.84 \%$ of respondents had $1-2$ children while only $0.5 \%$ of respondents were nulliparous. Regarding the predictor related to fertility, around $70 \%$ of women in this study did not want to have another child in the future and those women had a good knowledge of fertile day which those women answered correctly that fertile period occurred in between two menstrual period. However, based on frequency of visited fieldworker in the last 12 months, only $4 \%$ women in the study visited by fieldworker (table 1 ). Modern contraceptive used was more prevalent among women who lived in rural areas and in the Java-Bali islands.

Table 2 presents the distribution among LARC users in Indonesia. Compared to other modern contraceptive users, LARC users were higher parity, older, more educated, and wealthier. All possible determinants were tested in the bivariable analysis based on p-value $<0.05$. In bivariate analyses, there were no significant differences in LARC use by place of residence and region.

In the final model with adjusted for other factors related to fertility and socio-demographic, the significant predictors that influenced LARC used were women's age, parity, education, women's occupation, future desire of children and visiting of fieldworker (table 3). The adjusted odds ratio was higher among women aged 20-49 years by 1.8 times relative to younger women aged $15-19$ years. High educated women were 2.56 times more likely to adopt LARC than women with primary education or less. The adoption of LARC among women who wanted to have another child in the future was low compared to women who did not want to have children. Despite the proportion of women who visited by fieldworker was still low, but the result showed the significant influence on the adoption of LARC. Women who visited by fieldworkers were 1.31 more likely to use LARC than those who did not visited by fieldworker.

The final model in the table 3 showed parous women, especially those who had three or more children had higher odds of LARC used compared to those who had two or less children or nulliparous women (aOR: 82.4; 95\% CI: 11-610). Women with secondary education (aOR: 1.34; 95\% CI: 1.18-1.52) and women with higher education (aOR: 2.56; 95\% CI: 2.16-3.04) had higher odds of the used of LARC compared to those women with primary education or no education. Based on women's occupation, the used of LARC among women who work in agriculture (aOR: 1.34; 95\% CI: 1.18-1.52) were higher than those who did not work, but the used of LARC was no difference between women who did not work and women who worked in sectors other than agriculture. Some of socio-economic and geographical factors (knowledge about fertile day, mass media exposure, welfare, residence and region) were not significantly associated with the used of LARCS and were not included in the final multivariate logistic regression model.

\section{Discussion}

The Indonesia family planning program has made an important contribution in reducing fertility and maternal mortality since its initiation in early 1970s. The increase of modern contraceptive methods in the last three decades in Indonesia was contributed by the most populous contraceptive in Indonesia, injectables and oral contraception. Creating community demand for long-acting contraceptive methods is critical to achieved the targeted of $63.4 \%$ modern contraceptive prevalence rate in 2024 as it is mentioned in the Indonesia Midterm National Development Plan 2020-2024. Health provider is one of key persons to meet the target, so it is needed to improve their knowledge and skill on LARC methods. By enhancing provider's capacity, it will increase women's access to various contraceptive methods and allow women to get informed choice especially for women who have low knowledge about LARC methods (Barrett, Soon, Whitaker, Takekawa, \& Kaneshiro, 2012; Craig, Dehlendorf, Borrero, Harper, \& Rocca, 2014).

Results from the trend of contraceptive used demonstrated a gradual increase in the used of modern contraceptive methods. Between 1991 and 2017, there is an increase in the prevalence of reproductive women who used injectable, but a decrease in the used of LARC (BKKBN et al., 2017). IUDs and implants discontinuation in Indonesia were common because of side effects or health concerns (National Population and Family Planning Board et al., 2018). A study in Vietnam, IUD side effects which caused discontinuation were such as excessive menstrual bleeding, weight loss, infection and discomfort during sexual intercourse (Asad et al., 2019). Moreover, the health concerns related to implants were amenorrhea, prolonged bleeding, bleeding irregularity, infection emotional lability, weight increase and headache (Brache, Faundes, Alvarez, \& Cochon, 2002; Stoddard et al., 2011). Among women who discontinued their IUDs or implants choose to switch their LARCs to short-acting methods that could contribute to unwanted pregnancy due to inconsistent and incorrect use of the methods.

A-slow paced upward in LARC used during 2012-2017 suggests increasing availability of family planning services, improving access to public or private sector and improving the capacity of health providers to deliver family planning services. Based on descriptive characteristics, it can be known that more than $50 \%$ among women who used other contraception and do not want to stop their pregnancy still used short-acting contraceptive methods 
which high rate of discontinuation and less effective. Women who want limiting their pregnancies should be targeted by family planning program to switch their methods toward long-acting contraception.

In this study, parity was the most important factor that influence long-acting reversible contraceptive used that could be seen from the highest adjusted odds ratio in the final model. Based on the descriptive statistics, there was no nulliparous women who used IUDs or implants and only $0.5 \%$ nulliparous women who used short-acting contraceptive methods. The low usage of LARC methods among nulliparous women has found in many studies despite those women have no medical contraindication to use contraceptive methods (Dempsey et al., 2012; Kavanaugh, Jerman, \& Finer, 2015). The result of this study that multiparous women more likely to used LARC than childless women was consistent to another study (Adedini et al., 2019).

This study showed that only a few Indonesian women used modern contraception for delaying their first pregnancy. The reason for this may be that women want to be pregnant as soon as possible after their marriage since the high value of child ownership in Indonesia. Regarding to safety of contraception for nulliparous women, the previous studies showed the used on IUD did not affect future fertility to become pregnant following removal of the device (Delbarge et al., 2002; World Health Organization, 2015). The return of fertility, indicated by cumulative pregnancy rates, was $100 \%$ after 12 months of IUD removal for nulliparous women with the median to be pregnant was 6 months (Delbarge et al., 2002). Moreover, a study about LARC showed that intervention, such as evidence-based training for clinical providers related to accurate knowledge of medical eligibility of LARC use, counseling and clinical skill, can improve counseling and access to LARC especially for nulliparous women (Gibbs et al., 2016). Therefore, it is important for nulliparous women to receive comprehensive and accurate information and counselling about pros and cons of IUDs and implants including effectiveness, safety, acceptability, accessibility, affordability and the impact of contraception on subsequent fertility.

Regarding women's age, this study showed that the used of LARC among older women were higher than younger women (aOR 1.8, 95\% CI 1.03-3.22). This may be because younger women preferred to use short-acting methods as their contraception for spacing or delaying their pregnancies, while older women have completed their fertility. This result was in line with prior studies in many countries (Adedini et al., 2019; Austad et al., 2018; Bhandari et al., 2019; Weber et al., 2017). Barriers to use LARC by adolescents were including lack of knowledge and attitudes about LARC, limited access and high cost of initiation (Kavanaugh, Jerman, Ethier, \& Moskosky, 2013; Secura \& McNicholas, 2013; Weber et al., 2017). However, some studies found that more than 50\% adolescent aged 14-24 years had positive attitude toward IUD after being educational intervention about IUDs which informed about the effectiveness, insertion, removal, side effect, and cost of using IUDs (Mestad et al., 2011; Whitaker et al., 2008). Therefore, IUD were promoted as a first-line contraceptive methods for adolescents to delay their pregnancies (Mestad et al., 2011). It is important to ensure the provision of LARC methods and ensure the capacity and skills of health providers in providing family planning services.

As regards future desire of children, women who want to limit their pregnancy were more likely to adopt LARC than those who want another child. This result was consistent to other studies (Adedini et al., 2019). Long-acting methods were common used by older women who had already reached their fertility goals. Women, who did not have desire children in the future, were prefer to choose IUDs or implants rather than tubectomy because with the similar effectivity as sterilization, by using LARC women did not have the risk of regret (Finer et al., 2012).

Furthermore, our results showed higher uptake of LARC methods among higher educated women compared to women with primary or less education. The plausible reason for this was educated women had more knowledge related to the benefit of family planning program and they more likely to afford contraception to prevent their pregnancies.

The odds of using long-acting reversible contraceptive methods compared to using other modern contraceptive methods for women whose visited by fieldworker in the last 12 months was higher compared to women who did not visited by fieldworker in the last 12 months. This finding is important for family planning program since based on the respondent's characteristics only less than $4 \%$ of respondents were visited by fieldworkers. The reason for this may be that women who visited by fieldworker get comprehensive family planning information and counselling, so they can choose long-acting reversible contraception as their appropriate contraceptive method. Therefore, communication skills among fieldworker need to be enhanced to do counselling and work closely with the community member. Competence fieldworkers are critical to promote community demand on long-acting reversible contraception since they are at the forefront line who work closely with the community member. This finding is consistent with other research which show the importance of information dissemination by family planning workers and the choice of contraceptive methods (Harzif et al., 2019).

The strength of the study is based on nationally representative and large data. However, some factors related to 
contraceptive methods are not included in this study and the cross-sectional data do not allow to assess a causal relationship. This study, however, has limitations. The study was based on secondary data analysis, important context related to fertility and cultural factors could not be known because the factors were not available in the dataset. Another limitation is due to the cross-sectional design that cannot describe the cause and effect relationship. Further study is needed to investigate women's perceptions of LARC methods and the barriers in relation to their resistance to change to LARC method.

\section{Conclusion}

In conclusion, this study revealed a low used in long-acting reversible contraception even though those methods were effective and efficient to prevent the unintended pregnancies. LARC use was associated with older age, higher parity, higher education, visited by fieldworker and desire of no more children. Communication skills among fieldworker need to be enhanced to do counselling and work closely with the community member.

\section{Acknowledgements}

This study used the dataset from the 2017 Indonesia Demographic and Health Survey. The authors would like to thank to DHS Program for giving the permission to use the IDHS 2017 data for this analysis.

\section{Competing Interests Statement}

The author declares that there are no competing or potential conflicts of interest.

\section{References}

Adedini, S. A., Omisakin, O. A., \& Somefun, O. D. (2019). Trends, patterns and determinants of long-acting reversible methods of contraception among women in sub-Saharan Africa. PLoS ONE, 14(6), 1-16. https://doi.org/10.1371/journal.pone.0217574

Asad, S., Hebert, C., Andridge, R., Nguyen, N., \& Gallo, M. F. (2019). Changes in the use of effective and long-acting reversible contraception in Vietnam. Contraception, 99(3), 165-169. https://doi.org/10.1016/j.contraception.2018.11.014

Austad, K., Shah, P., \& Rohloff, P. (2018). Correlates of long-acting reversible contraception uptake among rural women in Guatemala. PLoS ONE, 13(6), 1-11. https://doi.org/10.1371/journal.pone.0199536

Barrett, M., Soon, R., Whitaker, A. K., Takekawa, S., \& Kaneshiro, B. (2012). Awareness and Knowledge of the Intrauterine Device in Adolescents. Journal of Pediatric and Adolescent Gynecology, 25(1), 39-42. https://doi.org/10.1016/j.jpag.2011.08.007

Bhandari, R., Pokhrel, K. N., Gabrielle, N., \& Amatya, A. (2019). Long acting reversible contraception use and associated factors among married women of reproductive age in Nepal. PLOS ONE, 14(3), 1-13. https://doi.org/10.1371/journal.pone.0214590

BKKBN, Kementerian Kesehatan, Kementerian PPN/Bappenas, FP2020, UNFPA, \& Embassy of Canada. (2017). A Rights-based Strategy for Accelerating Access to Integrated Family Planning and Reproductive Health Services to Achieve Indonesia 's Development Goals. Jakarta.

Brache, V., Faundes, A., Alvarez, F., \& Cochon, L. (2002). Nonmenstrual adverse events during use of implantable contraceptives for women: data from clinical trials. Contraception, 65(1), 63-74. https://doi.org/10.1016/S0010-7824(01)00289-X

Craig, A. D., Dehlendorf, C., Borrero, S., Harper, C. C., \& Rocca, C. H. (2014). Exploring young adults' contraceptive knowledge and attitudes: Disparities by race/ethnicity and age. Women's Health Issues, 24(3), e281-e289. https://doi.org/10.1016/j.whi.2014.02.003

Delbarge, W., Bátár, I., Bafort, M., Bonnivert, J., Colmant, C., Dhont, M., ... Wildemeersch, D. (2002). Return to fertility in nulliparous and parous women after removal of the GyneFix intrauterine contraceptive system. The European Journal of Contraception \& Reproductive Health Care, 7(1), 24-30.

Dempsey, A. R., Billingsley, C. C., Savage, A. H., \& Korte, J. E. (2012). Predictors of long-acting reversible contraception use among unmarried young adults. American Journal of Obstetrics \& Gynecology, 206(6), 526.e1-526.e5. https://doi.org/10.1016/j.ajog.2012.02.014

Fekadu, G. A., Omigbodun, A. O., Roberts, O. A., \& Yalew, A. W. (2019). Factors associated with long acting and permanent contraceptive methods use in Ethiopia. Contraception and Reproductive Medicine, 4(1), 1-11. https://doi.org/10.1186/s40834-019-0091-3

Finer, L. B., Jerman, J., \& Kavanaugh, M. L. (2012). Changes in use of long-acting contraceptive methods in the 


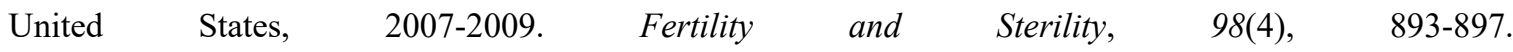
https://doi.org/10.1016/j.fertnstert.2012.06.027

Frost, J. J., \& Darroch, J. E. (2008). Factors Associated with Contraceptive Choice and Inconsistent Method Use, United States, 2004. Perspectives on Sexual and Reproductive Health, 40(2), 94-104. https://doi.org/10.1363/4009408

Gibbs, S. E., Rocca, C. H., Bednarek, P., Thompson, K. M. J., Darney, P. D., \& Harper, C. C. (2016). Long-Acting Reversible Contraception Counseling and Use for Older Adolescents and Nulliparous Women. Journal of Adolescent Health, 59(6), 703-709. https://doi.org/10.1016/j.jadohealth.2016.07.018

Harzif, A. K., Mariana, A., Malik, D. M., Silvia, M., \& Lovita, B. T. (2019). Factors associated with the utilization of long-acting reversible contraceptives among family planning clients at the Pameungpeuk Rural Hospital, Indonesia. F1000Research, 7, 1891. https://doi.org/10.12688/f1000research.15755.2

ICF. (2018). Demographic and Health Surveys: Standard Recode Manual for DHS 7. Rockville, Maryland, USA: The Demographic and Health Surveys Program.

Kavanaugh, M. L., Jerman, J., Ethier, K., \& Moskosky, S. (2013). Meeting the contraceptive needs of teens and young adults: Youth-friendly and long-acting reversible contraceptive services in U.S. family planning facilities. Journal of Adolescent Health, 52(3), 284-292. https://doi.org/10.1016/j.jadohealth.2012.10.276

Kavanaugh, M. L., Jerman, J., \& Finer, L. B. (2015). Changes in Use of Long-Acting Reversible Contraceptive Methods Among U.S. Women, 2009-2012. Obstetrics \& Gynecology, 126(5), 1. https://doi.org/10.1097/AOG.0000000000001094

Mazzei, A., Ingabire, R., Mukamuyango, J., Nyombayire, J., Sinabamenye, R., Bayingana, R., ... Wall, K. M. (2019). Community health worker promotions increase uptake of long-acting reversible contraception in Rwanda. Reproductive Health, 16(1), 1-11. https://doi.org/10.1186/s12978-019-0739-0

Mestad, R., Secura, G., Allsworth, J. E., Madden, T., Zhao, Q., \& Peipert, J. F. (2011). Acceptance of long-acting reversible contraceptive methods by adolescent participants in the Contraceptive CHOICE Project. Contraception, 84(5), 493-498. https://doi.org/10.1016/j.contraception.2011.03.001

National Population and Family Planning Board, Statistics Indonesia, Ministry of Health, \& ICF. (2018). Indonesia Demographic and Health Survey 2017. Jakarta.

Ontiri, S., Ndirangu, G., Kabue, M., Biesma, R., Stekelenburg, J., \& Ouma, C. (2019). Long-acting reversible contraception uptake and associated factors among women of reproductive age in rural Kenya. International Journal of Environmental Research and Public Health, 16(9), 1-11. https://doi.org/10.3390/ijerph16091543

Peipert, J. F., Zhao, Q., Allsworth, J. E., Petrosky, E., Madden, T., Eisenberg, D., \& Secura, G. (2013). Continuation and Satisfaction of Reversible Contraception. Obstet Gynecology, 117(5), 1105-1113. https://doi.org/10.1097/AOG.0b013e31821188ad.Continuation

Sakshaug, J. W., \& West, B. T. (2014). Important Considerations When Analyzing Health Survey Data Collected Using a Complex Sample Design. American Journal of Public Health, 104(1), 15-16. https://doi.org/10.2105/AJPH.2013.301515

Secura, G. M., \& McNicholas, C. (2013). Long-acting reversible contraceptive use among teens prevents unintended pregnancy: A look at the evidence. Expert Review of Obstetrics and Gynecology, 8(4), 297-299. https://doi.org/10.1586/17474108.2013.811942

Smith, R., Ashford, L., Gribble, J., \& Clifton, D. (2009). Family planning saves lives (Fourth Edi). Washington, DC: Population Reference Bureau. https://doi.org/10.1016/0020-7292(90)90486-5

Starbird, E., Norton, M., \& Marcus, R. (2016). Investing in family planning: Key to achieving the sustainable development goals. Global Health Science and Practice, 4(2), 191-210. https://doi.org/10.9745/GHSP-D-15-00374

Stoddard, A., McNicholas, C., \& Peipert, J. F. (2011). Efficacy and Safety of Long-Acting Reversible Contraception. Drugs, 71(8), 969-980. https://doi.org/10.2165/11591290-000000000-00000.Efficacy

Trussell, J. (2004). Contraceptive failure in the United States. Contraception, 70(2), 89-96. https://doi.org/10.1016/j.contraception.2004.03.009

Wang, H., Abajobir, A. A., Abate, K. H., Abbafati, C., Abbas, K. M., Abd-Allah, F., ... Murray, C. J. L. (2017). Global, regional, and national under-5 mortality, adult mortality, age-specific mortality, and life expectancy, 
1970-2016: A systematic analysis for the Global Burden of Disease Study 2016. The Lancet, 390, 1084-1150. https://doi.org/10.1016/S0140-6736(17)31833-0

Weber, T. L., Briggs, A., \& Hanson, J. D. (2017). Exploring the Uptake of Long-Acting Reversible Contraception in South Dakota Women and the Importance of Provider Education. S D Med, 70(11), 493-297. https://doi.org/10.1016/j.physbeh.2017.03.040

Whitaker, A. K., Johnson, L. M., Harwood, B., Chiappetta, L., Creinin, M. D., \& Gold, M. A. (2008). Adolescent and young adult women's knowledge of and attitudes toward the intrauterine device. Contraception, 78(3), 211-217. https://doi.org/10.1016/j.contraception.2008.04.119

World Health Organization. (2015). Medical eligibility criteria for contraceptive use (Fifth edit). Geneva: WHO Press.

\section{Appendix}

Table 1. Socio-demographic characteristics of modern contraception users, IDHS 2017

\begin{tabular}{|c|c|c|c|c|}
\hline \multirow{2}{*}{$\begin{array}{l}\text { Variables } \\
\text { Age in years }\end{array}$} & \multirow[t]{2}{*}{ LARC } & \multirow[t]{2}{*}{ Other modern contraception } & \multicolumn{2}{|c|}{ Women Who Used Modern Contraception } \\
\hline & & & & \\
\hline$-\quad 15-19$ & 21 & 286 & 307 & $1.50 \%$ \\
\hline$-\quad 20-34$ & 1,444 & 7,497 & 8941 & $43.81 \%$ \\
\hline$-\quad 35-49$ & 1,910 & 9,251 & 11162 & $54.69 \%$ \\
\hline \multicolumn{5}{|l|}{ Parity } \\
\hline-0 & 0 & 105 & 105 & $0.51 \%$ \\
\hline$-\quad 1-2$ & 2,087 & 10,739 & 12,826 & $62.84 \%$ \\
\hline$-\quad 3+$ & 1,287 & 6,191 & 7,479 & $36.64 \%$ \\
\hline \multicolumn{5}{|l|}{ Education } \\
\hline - $\quad$ No education \& primary & 1,046 & 6,646 & 7,693 & $37.69 \%$ \\
\hline - Secondary & 1,776 & 8,949 & 10,725 & $52.55 \%$ \\
\hline - Higher & 552 & 1,439 & 1,991 & $9.76 \%$ \\
\hline \multicolumn{5}{|l|}{ Occupation of women } \\
\hline - $\quad$ Not Working & 1,242 & 6,957 & 8,200 & $40.18 \%$ \\
\hline - $\quad$ Agriculture & 515 & 2,576 & 3,091 & $15.14 \%$ \\
\hline$-\quad$ Others & 1,618 & 7,502 & 9,119 & $44.68 \%$ \\
\hline \multicolumn{5}{|l|}{ Future desire of children } \\
\hline - No more & 2,235 & 10,580 & 12,814 & $62.79 \%$ \\
\hline - Have another in future & 1,140 & 6,455 & 7,595 & $37.21 \%$ \\
\hline \multicolumn{5}{|l|}{ Knowledge about Fertile day } \\
\hline$-\quad$ No & 914 & 5,400 & 6,314 & $30.94 \%$ \\
\hline$-\quad$ Yes & 2,461 & 11,634 & 14,095 & $69.06 \%$ \\
\hline \multicolumn{5}{|l|}{ Mass media exposure } \\
\hline - $\quad$ No exposure & 1,261 & 7,016 & 8,277 & $40.55 \%$ \\
\hline - $\quad$ At least one exposure & 2,114 & 10,019 & 12,133 & $59.45 \%$ \\
\hline \multicolumn{5}{|c|}{ Visited by fieldworker in the 12 months } \\
\hline$-\quad$ No & 3,214 & 16,419 & 19,633 & $96.20 \%$ \\
\hline$-\quad$ Yes & 161 & 615 & 776 & $3.80 \%$ \\
\hline \multicolumn{5}{|l|}{ Wealth Index } \\
\hline - $\quad$ Least wealthy & 1,220 & 6,686 & 7,906 & $38.73 \%$ \\
\hline - $\quad$ Middle & 670 & 3,736 & 4,406 & $21.59 \%$ \\
\hline - Wealthiest & 1,485 & 6,613 & 8,098 & $39.68 \%$ \\
\hline
\end{tabular}




\begin{tabular}{lrrrr}
\hline Residence & & & & \\
$-\quad$ Urban & 1,632 & 7,869 & 9,501 & $46.55 \%$ \\
$-\quad$ Rural & 1,743 & 9,166 & 10,909 & $53.45 \%$ \\
\hline Region & & & & \\
$-\quad$ Java-Bali & 2,115 & 10,786 & 12,901 & $63.21 \%$ \\
$-\quad$ Outside Java-Bali & 1,260 & 6,248 & 7,508 & $36.79 \%$ \\
\hline Total & $\mathbf{3 , 3 7 5}$ & $\mathbf{1 7 , 0 3 5}$ & $\mathbf{2 0 , 4 0 9}$ & $\mathbf{1 0 0 \%}$ \\
\hline
\end{tabular}

Table 2. Distribution of LARC users in Indonesia, IDHS 2017

\begin{tabular}{|c|c|c|c|c|c|c|}
\hline Variables & $\begin{array}{l}\text { LARC } \\
\text { used }\end{array}$ & $\%$ & $\begin{array}{l}\text { Pearson } \\
\text { chi-square }\end{array}$ & p-value & $\begin{array}{l}\text { Crude Odds Ratio/COR } \\
(95 \% \mathrm{CI})\end{array}$ & p-value \\
\hline \multicolumn{7}{|l|}{ Age in years } \\
\hline$-\quad 15-19$ & 21 & 6.69 & 22.9053 & 0.000 & & \\
\hline$-\quad 20-34$ & 1,444 & 16.15 & & & $2.69(1.58-4.58)$ & 0.000 \\
\hline$-\quad 35-49$ & 1,910 & 17.11 & & & $2.88(1.68-4.94)$ & 0.000 \\
\hline \multicolumn{7}{|l|}{ Parity } \\
\hline$-\quad 0$ & 0 & 0 & 21.3284 & 0.000 & & \\
\hline$-\quad 1-2$ & 2,087 & 16.27 & & & $119.68(16.48-869.29)$ & 0.000 \\
\hline$-\quad 3+$ & 1,287 & 17.21 & & & $128.03(17.61-931.03)$ & 0.000 \\
\hline \multicolumn{7}{|l|}{ Education } \\
\hline $\begin{array}{l}\text { No education \& } \\
\text { primary }\end{array}$ & 1,046 & 13.60 & 208.3556 & 0.000 & & \\
\hline - $\quad$ Secondary & 1,776 & 16.56 & & & $1.26(1.11-1.43)$ & 0.000 \\
\hline - $\quad$ Higher & 552 & 27.74 & & & $2.44(2.07-2.87)$ & 0.000 \\
\hline \multicolumn{7}{|l|}{ Occupation of women } \\
\hline - $\quad$ Not Working & 1,242 & 15.15 & 19.0384 & 0.004 & & \\
\hline - $\quad$ Agriculture & 515 & 16.66 & & & $1.12(0.96-1.31)$ & 0.158 \\
\hline - $\quad$ Others & 1,618 & 17.74 & & & $1.21(1.08-1.34)$ & 0.001 \\
\hline \multicolumn{7}{|l|}{ Future desire of children } \\
\hline - No more & 2,235 & 17.44 & 18.5012 & 0.001 & $0.84(0.76-0.93)$ & 0.001 \\
\hline Have another in future & 1,140 & 15.01 & & & & \\
\hline \multicolumn{7}{|c|}{ Knowledge about Fertile day } \\
\hline$-\quad$ No & 914 & 14.47 & 25.6216 & 0.000 & & \\
\hline - Yes & 2,461 & 17.46 & & & $1.25(1.11-1.41)$ & 0.000 \\
\hline \multicolumn{7}{|l|}{ Mass media exposure } \\
\hline - $\quad$ No exposure & 1,261 & 15.23 & 15.5747 & 0.003 & & \\
\hline At least one exposure & 2,114 & 17.42 & & & $1.17(1.06-1.30)$ & 0.003 \\
\hline \multicolumn{7}{|c|}{ Visited by fieldworker in the 12 months } \\
\hline$-\quad$ No & 3,214 & 16.37 & 9.2864 & 0.014 & & \\
\hline - Yes & 161 & 20.72 & & & $1.33(1.06-1.68)$ & 0.014 \\
\hline \multicolumn{7}{|l|}{ Wealth Index } \\
\hline - Least wealthy & 1,220 & 15.43 & 28.9417 & 0.000 & & \\
\hline - $\quad$ Middle & 670 & 15.20 & & & $0.98(0.85-1.13)$ & 0.798 \\
\hline Wealthiest & 1,485 & 18.34 & & & $1.23(1.08-1.40)$ & 0.001 \\
\hline
\end{tabular}




\begin{tabular}{|c|c|c|c|c|c|c|c|}
\hline \multicolumn{8}{|c|}{ Residence } \\
\hline- & Urban & 1,632 & 17.18 & 4.8024 & 0.173 & & \\
\hline- & Rural & 1,743 & 15.98 & & & $0.92(0.81-1.04)$ & 0.173 \\
\hline \multicolumn{8}{|c|}{ Region } \\
\hline- & Java-Bali & 2,115 & 16.39 & 0.4682 & 0.652 & & \\
\hline- & Outside Java-Bali & 1,260 & 16.78 & & & $1.03(0.91-1.16)$ & 0.652 \\
\hline \multicolumn{2}{|c|}{ Total } & 3,375 & 16.54 & & & & \\
\hline
\end{tabular}

Table 3. Effects if of socio economic and fertility related factor on the used of LARC in Indonesia, IDHS 2017

\begin{tabular}{|c|c|c|c|c|c|}
\hline \multirow{2}{*}{\multicolumn{2}{|c|}{ Variables }} & \multicolumn{2}{|l|}{ Model I (Full model) } & \multicolumn{2}{|c|}{ Model II (Final Model) } \\
\hline & & Adj Odds Ratio & p-value & Adj Odds Ratio & p-value \\
\hline \multicolumn{6}{|c|}{ Age in years } \\
\hline & $15-19$ & & & & \\
\hline- & $20-34$ & $1.82(1.06-3.13)$ & 0.030 & $1.83(1.06-3.15)$ & 0.030 \\
\hline- & $35-49$ & $1.82(1.03-3.20)$ & 0.038 & $1.82(1.03-3.22)$ & 0.039 \\
\hline \multicolumn{6}{|c|}{ Parity } \\
\hline \multicolumn{6}{|c|}{$-\quad 0$} \\
\hline- & $1-2$ & $78.19(10.60-576.78)$ & 0.000 & $78.78(10.69-580.60)$ & 0.000 \\
\hline- & $3+$ & $81.87(11.05-606.54)$ & 0.000 & $82.41(11.13-610.10)$ & 0.000 \\
\hline \multicolumn{6}{|c|}{ Education } \\
\hline \multicolumn{6}{|c|}{ - $\quad$ No education $\&$ primary } \\
\hline- & Secondary & $1.32(1.16-1.49)$ & 0.000 & $1.34(1.18-1.52)$ & 0.000 \\
\hline- & Higher & $2.49(2.09-2.97)$ & 0.000 & $2.56(2.16-3.04)$ & 0.000 \\
\hline \multicolumn{6}{|c|}{ Occupation of women } \\
\hline \multicolumn{6}{|c|}{ - $\quad$ Not Working } \\
\hline- & Agriculture & $1.23(1.04-1.45)$ & 0.015 & $1.22(1.04-1.44)$ & 0.015 \\
\hline- & Others & $1.06(0.95-1.19)$ & 0.285 & $1.06(0.95-1.18)$ & 0.307 \\
\hline \multicolumn{6}{|c|}{ Future desire of children } \\
\hline \multicolumn{6}{|c|}{ - $\quad$ No more } \\
\hline- & Have another in future & $0.84(0.74-0.95)$ & 0.005 & $0.84(0.74-0.95)$ & 0.005 \\
\hline \multicolumn{6}{|c|}{ Visited by fieldworker in the 12 months } \\
\hline \multicolumn{6}{|c|}{$-\quad$ No } \\
\hline- & Yes & $1.29(1.02-1.62)$ & 0.031 & $1.31(1.04-1.65)$ & 0.023 \\
\hline \multicolumn{6}{|c|}{ Knowledge about Fertile day } \\
\hline \multicolumn{6}{|c|}{$-\quad$ No } \\
\hline- & Yes & $1.11(0.98-1.25)$ & 0.092 & & \\
\hline \multicolumn{6}{|c|}{ Mass media exposure } \\
\hline \multicolumn{6}{|c|}{ - $\quad$ No exposure } \\
\hline- & At least one exposure & $1.10(0.99-1.22)$ & 0.079 & & \\
\hline \multicolumn{6}{|c|}{ Wealth Index } \\
\hline \multicolumn{6}{|c|}{ - $\quad$ Least wealthy } \\
\hline- & Middle & $0.92(0.80-1.06)$ & 0.232 & & \\
\hline- & Wealthiest & $0.94(-.82-1.08)$ & 0.415 & & \\
\hline \multicolumn{6}{|c|}{ Residence } \\
\hline & Urban & & & & \\
\hline- & Rural & & & & \\
\hline
\end{tabular}




\section{Region}

- Java-Bali

- $\quad$ Outside Java-Bali

\section{Copyrights}

Copyright for this article is retained by the author(s), with first publication rights granted to the journal.

This is an open-access article distributed under the terms and conditions of the Creative Commons Attribution license (http://creativecommons.org/licenses/by/4.0/). 